\title{
Publisher Correction: Microwave photons emitted by fractionally charged quasiparticles
}

\author{
R. Bisognin ${ }^{1}$, H. Bartolomei ${ }^{1}$, M. Kumar ${ }^{1}$, I. Safi ${ }^{2}$, J.-M. Berroir ${ }^{1}$, E. Bocquillon ${ }^{1}$, B. Plaçais ${ }^{1}$, A. Cavanna (D) ${ }^{3}$, \\ U. Gennser (iD ${ }^{3}, Y . \operatorname{Jin}^{3} \&$ G. Fève (iD ${ }^{1}$
}

Correction to: Nature Communications https://doi.org/10.1038/s41467-019-09758-x, published online 12 April 2019

The original version of this Article contained an error in the author affiliations. Affiliation 3 incorrectly read "Centre de Nanosciences et de Nanotechnologies (C2N), CNRS, Univ. Paris Sud, Université Paris-Saclay, 91190, Saint-Aubin, France”. This has now been corrected in both the PDF and HTML versions of the Article.

This has now been corrected in both the PDF and HTML versions of the Article.

Published online: 15 May 2019

\begin{abstract}
cc) Open Access This article is licensed under a Creative Commons Attribution 4.0 International License, which permits use, sharing, adaptation, distribution and reproduction in any medium or format, as long as you give appropriate credit to the original author(s) and the source, provide a link to the Creative Commons license, and indicate if changes were made. The images or other third party material in this article are included in the article's Creative Commons license, unless indicated otherwise in a credit

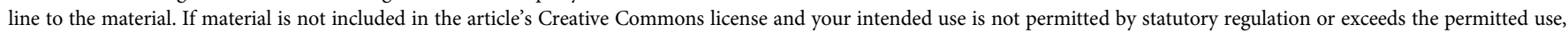
you will need to obtain permission directly from the copyright holder. To view a copy of this license, visit http://creativecommons.org/licenses/by/4.0/.
\end{abstract}

(C) The Author(s) 2019

\footnotetext{
${ }^{1}$ Laboratoire de Physique de I' Ecole normale supérieure, ENS, Université PSL, CNRS, Sorbonne Université, Université Paris-Diderot, Sorbonne Paris Cité, 75005 Paris, France. ${ }^{2}$ Laboratoire de Physique des Solides, Université Paris-Saclay, 91405 Orsay, France. ${ }^{3}$ Centre de Nanosciences et de Nanotechnologies (C2N), CNRS, Univ. Paris Sud, Université Paris-Saclay, 91120 Palaiseau, France. Correspondence and requests for materials should be addressed to G.F. (email: gwendal.feve@ens.fr)
} 